\title{
Mediation of seasonal testicular regression by apoptosis
}

\author{
Kelly A. Young ${ }^{1}$ and Randy J. Nelson ${ }^{2 *}$ \\ ${ }^{1}$ Division of Reproductive Sciences, Oregon Regional Primate Research Center, \\ Oregon Health Sciences University, 505 NW 185th Avenue, Beaverton, OR 97006, USA; \\ and ${ }^{2}$ Departments of Psychology and Neuroscience, Ohio State University, Columbus, \\ $\mathrm{OH} 43210$, USA
}

\begin{abstract}
Animals restrict breeding to specific times of the year when reproductive success is most likely. In males, the most reliable method of reproductive inhibition is gonadal retrogression to an immature state. Depending on the species, the testes decrease in size by between 10 and $95 \%$ in response to environmental cues associated with the non-breeding season. An increased rate of apoptosis can occur during testicular regression, whereas little testicular apoptosis is observed during testicular recrudescence or during the breeding season. The Fas system is implicated as a potential mechanism to transmit the apoptotic signal to germ cells during regression, although many apoptotic pathways probably contribute to testicular regression. Finally, differences in both the contribution of testosterone and in the types of cell that undergo apoptosis differ between rodents and birds, indicating that different cellular mechanisms and possibly signals have evolved at the testis to suspend reproduction on a seasonal basis.
\end{abstract}

Seasonal rhythms in physiology and behaviour are characteristic of most temperate and boreal species (Bronson, 1989). Synchronizing energetically demanding biological functions to the most favourable time of the year enables individuals to cope with recurring stressors such as seasonal declines in food or water availability, or annual fluctuations in ambient temperature. Environmental factors such as food availability, social cues, ambient temperature and the initial predictive cue of daylength (photoperiod) can facilitate or inhibit reproductive function seasonally. These factors maintain testicular function during favourable times of the year in some species (for example, birds), and induce testicular regression or atrophy when environmental conditions are less favourable in others (for example, small mammals). Environmental factors regulate testicular function through the hypothalamic-pituitary-gonadal (HPG) axis. Photoperiod serves as the primary predictive factor in the regulation of reproductive timing in long- and short-day breeding mammals and in most bird species (Wingfield and Kenagy, 1991; Bronson and Heideman, 1994). The general long-day breeding rodent response to seasonal changes in daylength is shown (Fig. 1); however, the actual HPG response to photoperiod is distinct among different species of birds, reptiles and mammals. Supplementary cues such as food and water availability also affect reproductive function directly, serving to fine-tune the initial, general reproductive response to photoperiod (Wingfield and Kenagy, 1991). Environmental factors that stimulate or maintain reproduction promote synthesis and secretion of $\mathrm{GnRH}$ from the

*Correspondence

Email: rnelson@osu.edu hypothalamic median eminence, and positively regulate secretion of the gonadotrophins ( $\mathrm{LH}$ and $\mathrm{FSH}$ ) from the anterior pituitary (Bronson and Heideman, 1994). In contrast, non-stimulatory environmental factors decrease $\mathrm{GnRH}$ (pulse amplitude and frequency) release, resulting in testicular atrophy, reduced spermatogenesis and diminished testosterone production from Leydig cells, the steroidogenic somatic cells in the testicular interstitium (Sinha Hikim and Swerdloff, 1999).

During the transition from the breeding to the nonbreeding state, males in most seasonally breeding species undergo $40-90 \%$ atrophy in testis mass. Cells must either undergo marked reduction in size, increases in the rate of cell death, or both, to achieve the reduction in volume observed during regression. The rate of cell division may decrease in the testis during regression, indirectly contributing to seasonal atrophy; however, total testicular DNA content in rodents is reduced with non-stimulatory photoperiod exposure, indicating an increase in cell death during regression (Desjardins and Lopez, 1983). Recent studies have examined complex changes that occur in testicular cells during seasonal reproductive regression. In this review, the contribution of apoptosis, or programmed cell death, in the mediation of seasonal atrophy is discussed. Specifically, the review focuses on the interactions of gonadotrophins and gonadal sex steroid hormones with apoptosis during seasonal testicular atrophy.

In both the breeding and non-breeding state, the fate of male germ cells is highly dependent on the interaction between extracellular signals and the quality of the internal environment (Ewing et al., 1980). Both environmental and developmental cues can trigger apoptosis in the testis 


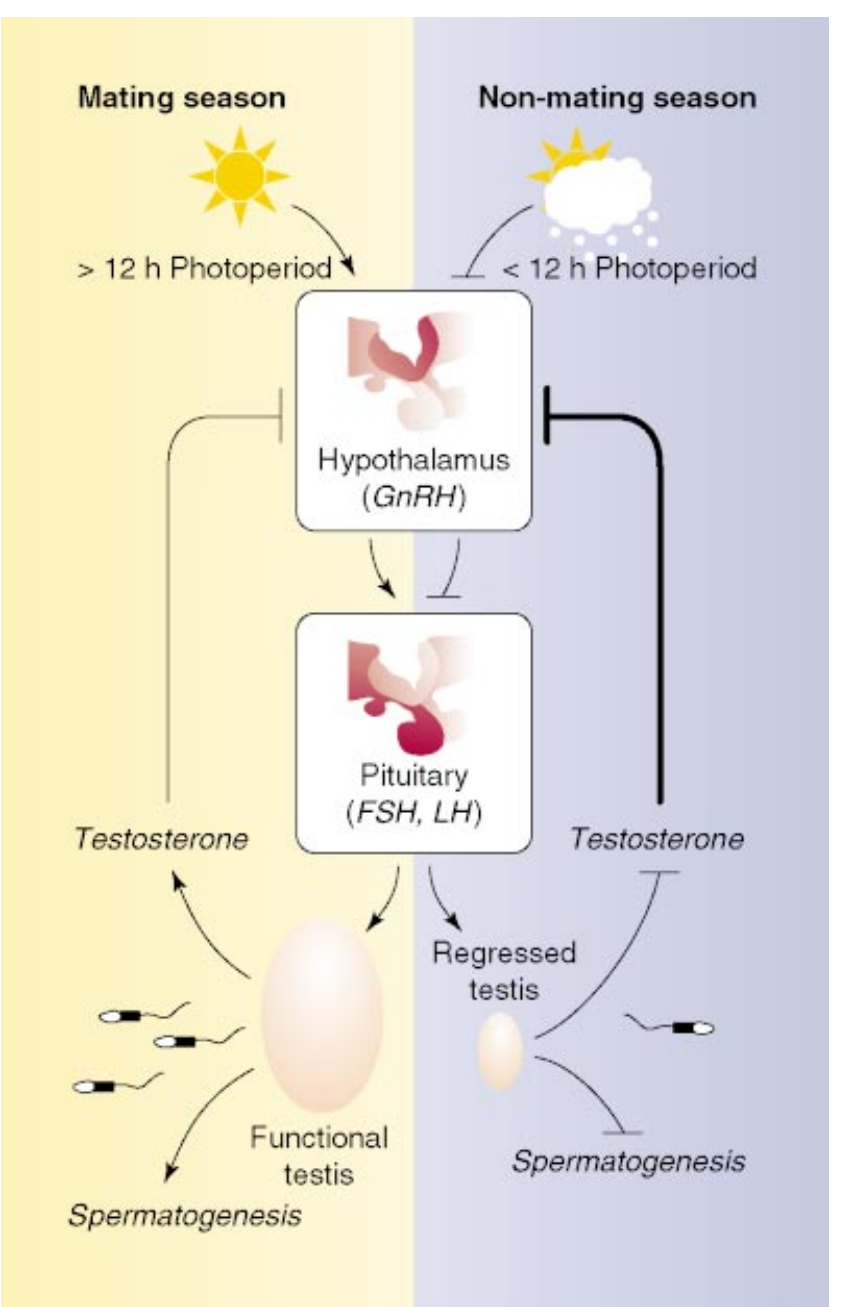

Fig. 1. Seasonal changes in hypothalamus-pituitary-gonadal axis (HPG) and corresponding changes in testis size and function for long-day breeding mammals such as hamsters and white-footed mice (Peromyscus leucopus). Long ( $>12 \mathrm{~h}$ of light per day) daylengths stimulate release of $\mathrm{GnRH}$ from the hypothalamus, thereby triggering synthesis and secretion of pituitary FSH and $\mathrm{LH}$. These gonadotrophins function to maintain both spermatogenesis and steroidogenesis in the testis. Short $(<12 \mathrm{~h}$ of light per day) photoperiods, typical of high latitude winters, inhibit $\mathrm{GnRH}$ release, effectively terminating production of both spermatozoa and testosterone.

(Thompson, 1994; Vaux and Strausser, 1996; Le Grand, 1997). Apoptotic pathways generated by a cascade of signalling events remove target cells without eruptive cell lysis. The completion of apoptotic cell death is ATP-dependent and differs morphologically from the passive loss of membrane integrity typical of necrosis (Corrier et al., 1985; Mikuz, 1985). Morphologically, apoptosis is identified by characteristic membrane blebbing, condensation of the nucleus, DNA fragmentation, and formation of the apoptotic bodies that are phagocytosed cleanly by adjacent cells (Vaux and Strausser, 1996; Le Grand, 1997). Apoptosis in the seasonally regressing testis can be assessed by a variety of molecular and in situ methods, including TUNEL labelling and DNA laddering. Both techniques take advantage of the approximately 180 base pair fragments generated by the activated CAD endonuclease at the termination of apoptotic cell death. In situ TUNEL permits identification of the dying cell type, whereas the ladderbanding pattern produced by radiolabelled DNA fragments on an agarose gel is the hallmark of general apoptosis within a tissue or type of cell.

Apoptosis is an integral component of normal testicular function and has been hypothesized to limit the germ cell population and prevent maturation of aberrant germ cells (Yin et al., 1998). Indeed, quantification of types of cell in the rodent seminiferous epithelium has shown that extant populations of preleptotene spermatocytes represent only $25 \%$ of the germ cells theoretically possible from dividing A1 spermatogonia (Allan et al., 1987). Apoptosis is also a feature in more advanced stages of spermatogenesis, and it has been estimated that up to $20 \%$ of germ cells undergo apoptosis between the preleptotene and spermatozoa stages (Allan et al., 1987). Cells that have undergone apoptosis are generally sloughed off into the tubule lumen or phagocytosed by Sertoli cells (Allan, et al., 1987; Tapanainen et al., 1993).

During atrophy of the testes, the dynamic relationship between cellular growth and development and apoptotic and necrotic cell death shifts towards cell death. The specific ratio of apoptotic:necrotic cell death occurring during regression is unknown, although, upon histological examination of regressing testes, cells displaying attributes of apoptosis are commonly reported, in contrast to the infrequent observation of cells exhibiting necrotic characteristics (Young et al., 1999, 2000). Degeneration of germinal epithelium in rats (Rattus norvegicus) and mice (Mus musculus) in response to hypophysectomy, gonadotrophin and GnRH antibody administration, severe temperature stress, and toxin exposure is associated with increased apoptotic cell death (Tapanainen et al., 1993; Hikim et al., 1995; Shetty et al., 1996; Lee, et al., 1997). Indeed, most studies of testicular apoptosis have examined pathological or supraphysiological states (for example, Franca et al., 2000; Zhu et al., 2000). Seasonal gonadal atrophy represents a natural model for the study of gonadal apoptosis.

In long-day breeding rodents, exposure to photoperiods that simulate summer or long ( $>12 \mathrm{~h}$ ) day conditions stimulates and sustains reproductive function. Testis mass in these males is maintained or increased, and the incidence of testicular apoptosis is low (Fig. 2). Similarly, when reproductively inhibited peripuburtal Djungarian hamsters (Phodopus sungorus) and white-footed mice (Peromyscus leucopus) are exposed to long-day conditions that stimulate increases in testis mass, the incidence of testicular apoptosis is low (Furuta et al., 1994; Young et al., 2001a). In adult males housed long term under breeding season conditions, both testis mass and the low rate of testicular apoptosis remain constant (Young et al., 1999, 2000). 
In contrast, exposure of rodents to 6-14 weeks of short photoperiods, typical of winter or the non-breeding season, induces testicular regression (Furuta et al., 1994; Young et al., 1999) (Fig. 2). In peripubertal Djungarian hamsters ( $P$. sungorus), apoptotic cell death is involved with testicular regression in response to short-day exposure (Furuta et al., 1994). Increases in apoptotic cell death occur rapidly after exposure to non-stimulatory photoperiods, and decrease after transfer to long daylengths. In peripubertal Djungarian hamsters, alterations in FSH secretion precede changes in DNA fragmentation, and are coincident with alterations in serum testosterone (Furuta et al., 1994). In contrast, changes in $\mathrm{LH}$ receptor content do not occur until after significant increases in DNA fragmentation, indicating that $\mathrm{LH}$ is not a key regulator in the onset of seasonal testicular regression. Instead, it appears that FSH secretion mediates the onset of testicular apoptosis during regression induced by short daylength in Djungarian hamsters (Furuta et al., 1994).

Similarly, in adult white-footed mice, testicular regression occurs after 8-14 weeks of exposure to short photoperiods (Young et al., 1999). Initial increases in apoptotic cell death precede significant testicular atrophy, and are detected after 4-6 weeks of exposure to short, as compared with long, daylengths (Fig. 2). The incidence of apoptosis increases over threefold after 6,8 and 10 weeks of exposure to short photoperiod, as compared with that of males exposed to long daylengths over the same period. After 14 weeks, recorded testis mass is minimal and apoptosis is increased more than sixfold in males exposed to short, compared with long, daylengths (Fig. 2) (Young et al., 2001a). Cell death remains high in the testis through 18 weeks of exposure to short daylengths, as assessed by both TUNEL labelling and DNA laddering.

Long-day breeding rodents exposed continuously to short photoperiods undergo a resurgence or recrudescence in reproductive function (Reiter, 1972). After 15-20 weeks of exposure to short daylengths, the HPG axis of seasonally breeding rodents is no longer responsive to the nonstimulatory short photoperiod signal, and reproductive function is reinstated spontaneously (Matt and Stetson, 1979; Schlatt et al., 1995). Continued exposure to short days results in a spontaneous regrowth or recrudescence of the testis. Regulation of testicular apoptosis is involved with this resurgence of reproductive function; decreased incidence of apoptosis is concomitant with regrowth of the testes (Fig. 2). In recrudescing males, positive TUNEL labelling and low molecular mass DNA returned to amounts typical of controls exposed to long days after 26 weeks of short photoperiod (Young et al., 2001a).

Increased apoptosis during testicular regression has also been investigated in an avian seasonal breeder, the European starling (Sturnus vulgaris). Long-day stimulation of photosensitive starlings induces a rapid cycle of testicular growth and atrophy. Photostimulation initiates significant growth of the testis after 3-4 weeks, followed by rapid gonadal regression after 5-9 weeks of exposure (Fig. 3). Relatively low apoptotic cell death characterizes the early

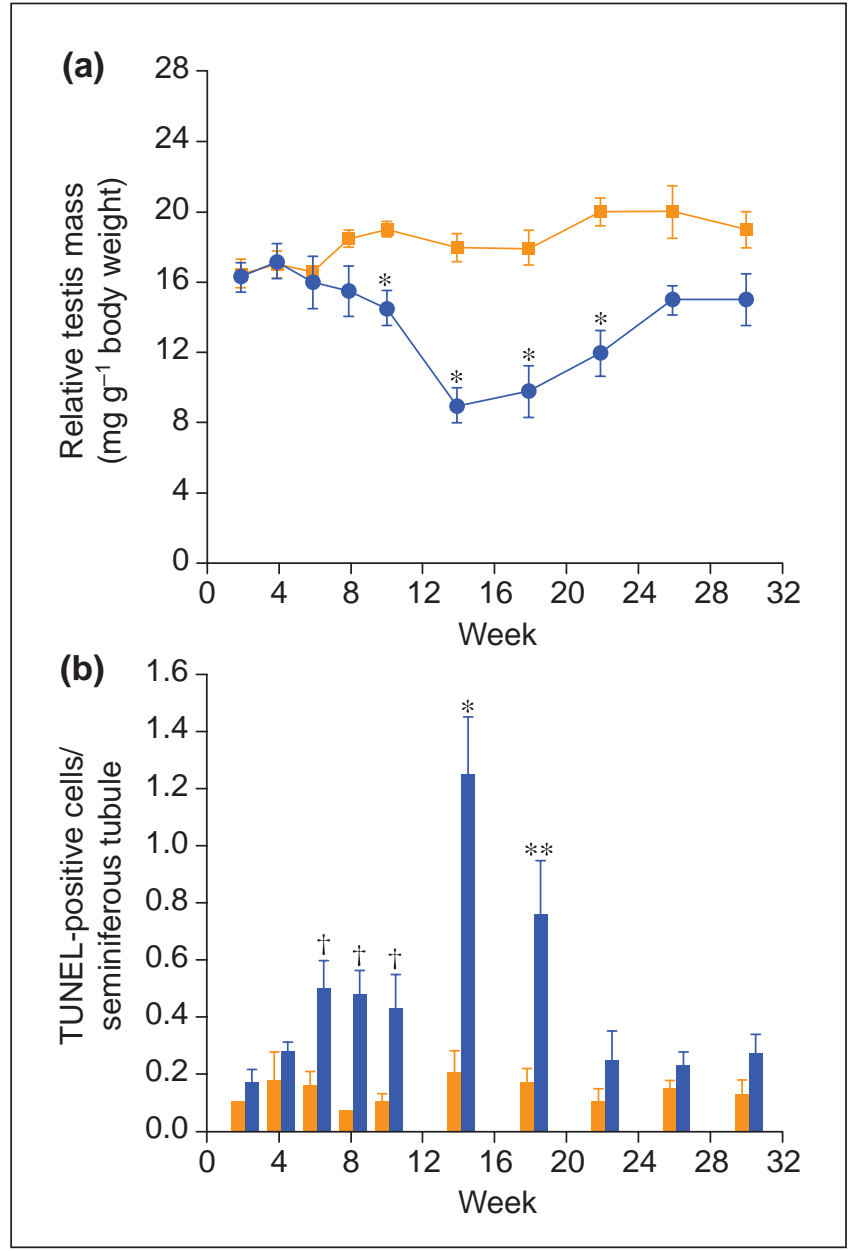

Fig. 2. (a) Relative testis mass (mg per g body weight) in whitefooted mice (Peromyscus leucopus) housed in long (16 h light: $8 \mathrm{~h}$ dark) (orange squares) or short ( $8 \mathrm{~h}$ light:16 h dark) (blue circles) days. *Significant difference compared with all long day males. (b) Quantification of TUNEL-positive cells within testis cross-sections. Mean ( \pm SEM) number of apoptotic cells per seminiferous tubule within each cross-section from white-footed mice housed in long (16 h light:8 h dark) (orange bars) or short (8 h light:16 h dark) (blue bars) days for up to 30 days. Bars sharing the same symbol do not differ significantly. *Significant difference compared with all mice; ${ }^{* *}$ significant difference compared with all long-day animals, and weeks 2, 4, 22, 26, and 30 of short-day animals; ${ }^{\dagger}$ significant difference compared with all long-day males, and weeks 2 and 26 of short-day males $(P<0.05)$. (Data compiled from Young et al., 1999, 2001a)

weeks of photostimulation, the period of testicular regrowth. Testicular cell death increases significantly after chronic photostimulation, increasing over sevenfold after 6 weeks of photostimulation (Young et al., 2001b). After 9 weeks, testes are fully regressed, and apoptosis has returned to baseline amounts. Testicular atrophy in starlings appears to be mediated in a similar manner to that of longday breeding rodents, by significant increases in apoptosis. During regression, the increase in testicular apoptotic activity compared with controls appears to be heightened in 


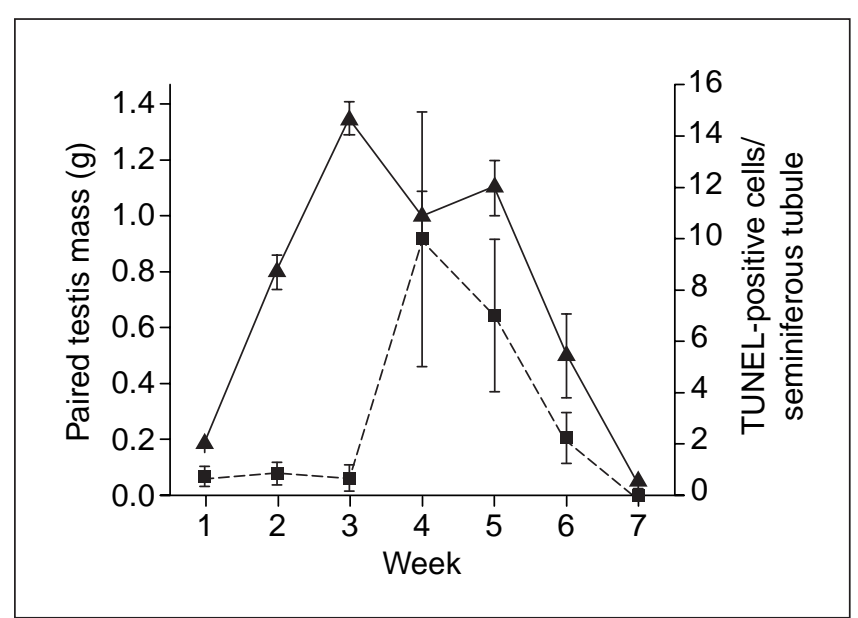

Fig. 3. Photoperiod-induced changes in testis mass and testicular apoptosis in European starlings (Sturnus vulgaris). The mean paired absolute testis mass (g) ( \pm SEM) changes significantly over 9 weeks of exposure to $18 \mathrm{~h}$ light photoperiods $(\boldsymbol{\Delta})$. Chronic exposure to 18 $h$ light also induces changes in the mean ( \pm SEM) number of TUNEL-positive germ cells per seminiferous tubule (ם). (Data compiled from Young et al., 2001b.)

European starlings compared with white-footed mice. An increased rate of apoptosis may contribute to the rapid testicular dismantling that is typical of starlings, but which is not observed during the longer regression periods of whitefooted mice.

\section{Food restriction}

The timing and extent of testicular apoptosis has also been investigated during regression induced by simultaneous exposure to two winter factors: food restriction and short photoperiod. Regardless of other environmental factors, a certain nutritional threshold must be achieved in order to maintain full reproductive function (Desjardins and Lopez, 1983; Nelson et al., 1992). Decreased food intake affects the HPG axis by suppressing pulsatile release of $\mathrm{GnRH}$ from the hypothalamus (Nelson et al., 1992). Both time of onset and extent of reproductive regression can be increased in the laboratory with concurrent exposure to multiple winter cues (Desjardins and Lopez, 1983). Dietary restriction provides both an acute cellular stressor and a cue for seasonal testicular regression (Nelson et al., 1992). In adult white-footed mice, both restriction of food intake and shortday exposure decrease testis mass and plasma testosterone concentrations. Maximum decreases in testis mass and plasma testosterone occur when male white-footed mice are exposed to both short days and restricted food intake. Increases in the incidence of apoptosis occur with initial exposure to food restriction in males exposed to long photoperiods. However, the simultaneous exposure to food restriction and short daylengths significantly increases the degree of testicular apoptosis in these mice (Fig. 4) (Young et al., 2000). The extent of testicular DNA laddering and
TUNEL labelling increase with chronic food restriction, and increases reach maximum values when males are both food restricted and exposed to short days (Fig. 4). These data indicate that both food restriction and short photoperiod interact additively to affect the rate of apoptosis in the regressing testis of white-footed mice.

\section{Role of testosterone}

Testosterone is a cell survival factor for germ cells in the testis. Withdrawal of testosterone induces apoptosis in the testis, and reintroduction of this steroid hormone can reduce apoptotic cell death in some situations (Nandi, 1999). Reductions of testosterone may contribute to the increased degree of apoptosis that occurs with continued exposure (6-10 weeks) of rodents to food restriction and short days (Furuta et al., 1994; Young et al., 1999, 2000). Among species examined for apoptotic cell death during seasonal regression, two distinct patterns of testosterone concentration and apoptotic cell death emerge: increases in cell death occurring before decreases in plasma testosterone concentrations, or increased apoptosis after declines in plasma testosterone.

In white-footed mice and Djungarian hamsters, the onset of testicular apoptosis appears not to be mediated by withdrawal of circulating testosterone (Furuta et al., 1994; Young et al., 1999). Increases in testicular apoptosis as a result of short photoperiods, food restriction, or both, occur before detectable decreases in serum testosterone concentrations in white-footed mice. Despite the importance of testosterone as a survival factor in the testis, this timing is indicative of pituitary regulation of apoptotic increases during seasonal atrophy. Indeed, both spermatogenesis and steroidogenesis are dependent upon gonadotrophin secretion; withdrawal of FSH and $\mathrm{LH}$ induces testicular atrophy and increases in apoptotic cell death (Russell et al., 1987; Tapanainen et al., 1993). Apoptotic DNA fragmentation is suppressed in hypophysectomized rats administered exogenous $\mathrm{FSH}$, and injection with $\mathrm{FSH}$ antiserum results in apoptotic germ cell death within $24 \mathrm{~h}$ (Russell et al., 1987; Shetty, et al., 1996).

Alternatively, it is possible that testosterone has a key regulatory role in the induction of apoptosis in these species. Increases in apoptotic cell death may reflect local decreases in testis testosterone concentrations not immediately detectable in the blood. Details of both intratesticular and plasma concentrations of testosterone are necessary before the relationship between testosterone and testicular apoptosis during seasonal regression can be clarified. In addition, other variables, such as expression of $3 \beta$-hydroxysteroid dehydrogenase (3 $\beta$-HSD), aromatase activity, oestradiol production, and cofactor regulation, can affect testis concentrations of testosterone (Sharpe, 1990), as well as pathways regulated by testosterone. Aromatase protein expression differs seasonally in bank vole (Clethrionomys glareolus) testes (Bilinska et al., 2000), as do testicular $3 \beta$-hydroxysteroid dehydrogenase concentrations 
in Japanese black bears (Ursus thibetanus japonicus) (Komatsu et al., 1997). Expression of these steroidogenic enzymes and other regulatory factors may also differ in other seasonally breeding species, affecting local apoptotic activity.

In contrast to the pattern of testosterone observed in long-day breeding rodents, plasma testosterone concentrations in starlings declined before substantial increases in testicular apoptosis. In starlings, testes atrophy rapidly, and the extent of regression exceeds what is typical in mammals. Increases in testicular apoptosis occur after a decrease in plasma testosterone, with plasma concentrations of testosterone reaching peak values after 2 weeks of $18 \mathrm{~h}$ light photostimulation, and significant increases in apoptotic cell death after 4 weeks of $18 \mathrm{~h}$ light photostimulation. The increase in testicular apoptosis is presumably the consequence of these endocrine changes, indicating that withdrawal of both gonadotrophins and testosterone influences the cellular events of testicular regression in European starlings. Early loss of testosterone may result in the large and rapid increases of testicular apoptosis observed during gonadal regression in starlings.

\section{Apoptosis specific to a type of cell}

During breeding season conditions, testes are fully functional with constant cycles of germ cell development (Fig. 5a). Somatic Sertoli cells support the maturation of spermatogonial daughter cells as they develop into spermatocytes, spermatids and, ultimately, spermatozoa. During testicular regression, the number of spermatozoa, spermatids, and spermatocytes is reduced (Fig. 5c). In the regressed testis of many species, the volume of Sertoli cells and steroidogenic Leydig cells is reduced, and spermatogonia are the predominant type of cell remaining in the seminiferous tubule (Fig. 5c).

The types of cell affected during testicular regression appear to differ among species. In both white-footed mice and European starlings, the majority of TUNEL-positive cells were spermatocytes, although some spermatogonia and spermatids labelled positively for cell death (Fig. 5b) (Young et al., 1999, 2001b). The primary type of cell labelling for apoptosis during seasonal testicular regression is the stage IV pachytene spermatocyte (Sinha Hikim et al., 1997), which produces a pattern of cell death similar to that observed during pharmacological gonadotrophin withdrawal. TUNEL labelling data in seasonal breeding species indicate that spermatocytes are most susceptible to perturbations in the seminiferous environment.

In white-footed mice, somatic cells did not label TUNELpositive, whereas in European starlings undergoing testicular regression, Sertoli cells were found to die via apoptosis (Fig. 5b) (Young et al., 2001b). Unlike germ cells, somatic cells such as Leydig and Sertoli cells are thought to occur as stable populations in the testis, and traditionally have been used to standardize the quantification of spermatogenesis (Clermont and Morgentaler, 1955; de Kretser and Kerr, 1994). During

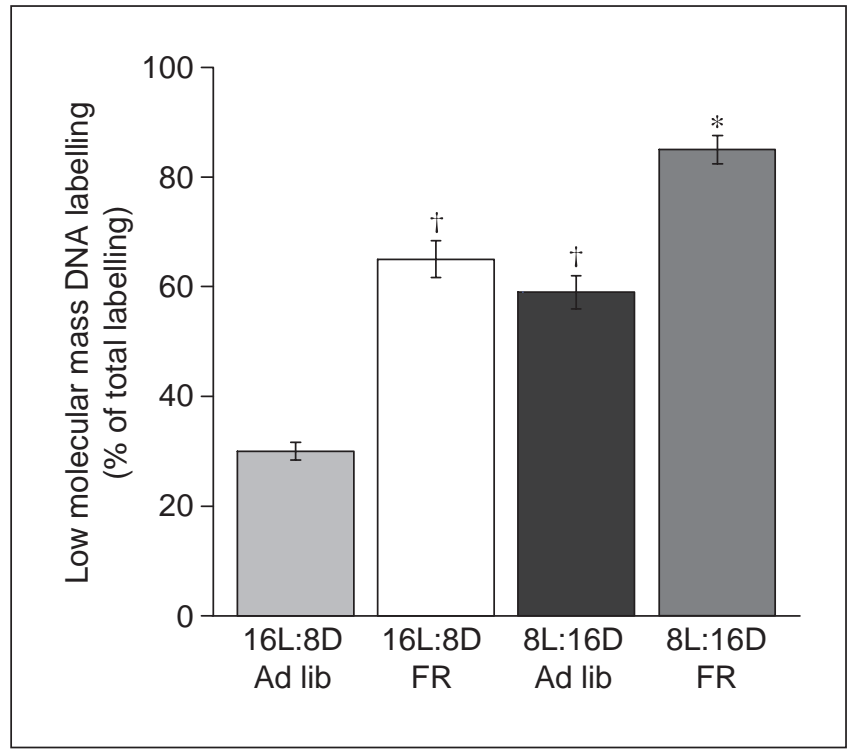

Fig. 4. Apoptotic DNA fragmentation in white-footed mice (Peromyscus leucopus) fed ad libitum or on a 30\% food-restricted diet and housed in long (16 h light:8 h dark) or short (8 h light:16 $\mathrm{h}$ dark) days. Bars represent the mean ( \pm SEM) percentage of low molecular mass labelling in animals housed for 8 weeks in experimental conditions ( $n=5$ per group). Results are expressed as a mean of individual low $(<15 \mathrm{~kb})$ molecular mass DNA fractions counts per minute to total lane counts per minute from five separate gel runs. *Significantly different compared with all mice; ${ }^{+}$significantly different compared with long-day males fed ad libitum. (Data compiled from Young et al., 1999, 2000.)

development, Sertoli cells and Leydig cells are dependent upon gonadotrophins (for example, FSH is necessary for the early proliferation of the Sertoli cell population and LH is necessary for stimulation of Leydig cell transformation from interstitial fibroblasts or mesenchymal cells), although hypophysectomy in rats does not induce morphological signs of apoptosis in either type of cell (Russell et al., 1994). Detection of apoptotic cell death in situ fails to label Sertoli cells in rats (Hikim et al., 1995; Billig et al., 1996) but in European starlings, Sertoli cells labelled TUNEL-positive (Fig. 5b). Sertoli cell death as a result of chronic photostimulation has been confirmed in European starlings using light and electron microscopy (Young, et al., 2001b). In European starlings, testicular regression is substantially more rapid and extensive than the regression that is typical in white-footed mice. Therefore, European starlings might be expected to display high gonadal apoptosis during regression in comparison with rodent species. It is interesting that the high rate of apoptosis involves a type of cell in the adult testis that is assumed to be stable (Clermont and Morgentaler, 1955). Regression in European starlings is unique among vertebrate species thus far examined in that both germ cells and Sertoli cells undergo cell death. Overall, there appears to be a difference in testicular regression between songbirds, like starlings, and rodents, indicating that distinct 


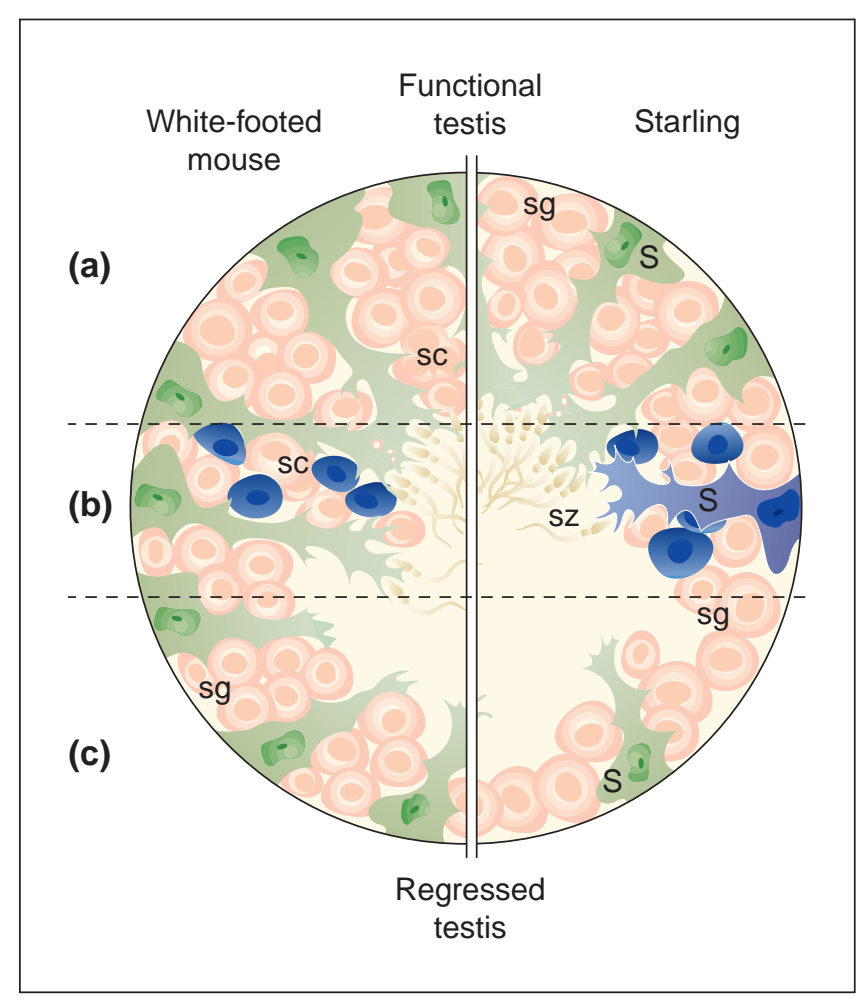

Fig. 5. Illustration of cellular changes in the testis during regression, showing generalized seminiferous tubule cross-sections from a white-footed mouse (Peromyscus leucopus) (left) and a European starling (Sturnus vulgaris) (right). (a) A fully functional testis. Somatic Sertoli cells (S) support spermatogonia (sg), spermatocytes (sc), spermatids (not depicted), and spermatozoa (sz, see label in (b)) in both species. (b) Seminiferous tubules from males undergoing regression are represented. During testicular regression, many cells undergo apoptosis as testis function and mass is reduced. TUNEL-labelled cells, positive for apoptosis, are blue. In white-footed mice, spermatocytes are the primary target for apoptosis during photoperiod-induced regression. In contrast, both Sertoli cells and spermatocytes label positive for TUNEL in starlings during regression. (c) A regressed testis. Spermatozoa, spermatids and most spermatocytes are no longer present. In both whitefooted mice and starlings, the testis consists primarily of atrophied Sertoli and Leydig (not depicted) cells and spermatogonial stem cells. (Data compiled from Young et al., 1999, 2001b.)

mechanisms have evolved to address parallel issues of seasonal gonadal function.

\section{Potential mechanisms of seasonal testicular regression}

Whereas apoptosis has been identified as mediating atrophy during seasonal testicular regression in several photoperiodic species, the mechanism of apoptosis in the seasonally regressing testis has not been widely studied. Transmission of death signals involves a variety of both constitutively expressed and inducible proteins and protein families, most of which have been examined for testis- specific function. When these families of death-related proteins are examined, two primary mechanisms of cell death emerge for the seasonally regressing testis: death by 'neglect' and death by 'design' (Fig. 6).

Apoptosis can be induced as a result of withdrawal of pro-life signals ('neglect'), such as growth and other survival factors secreted from other cells (Fig. 6a). Withdrawal of these signals often results in cell death mediated by proteins in the B-cell lymphoma/leukaemia-2 (BCl-2) family of apoptosis-associated genes. This family contains molecules, widely expressed in the testis, that can function as antideath (Bcl-2, Bcl- $\left.\mathrm{x}_{\mathrm{L}}, \mathrm{BCl}-\mathrm{w}\right)$, pro-death (Bax, Bak, Bcl- $\mathrm{x}_{\mathrm{s}}$ ) or both, depending on cell context and caspase cleavage (Srivastava et al., 1999). Proteins in this family are highly interactive, and the fate of cells is often determined by the relative ratios of family members. Ectopic expression of $\mathrm{BCl}-2$ in spermatogonia results in an accumulation of this type of cell, and a decrease in productive, mature, seminiferous tubules (Furuchi et al., 1996). Bcl-2 family members, Bcl-x and Bax, are critical promoters of germ cell survival during embryonic development and the first wave of spermatogenesis, respectively (Print and Loveland, 2000). In mice lacking $B C l-w$, adult spermatogenesis is disrupted, and TUNEL labelling in germ cells increased compared with control mice (Print et al., 1998). During testicular regression, withdrawal of growth or other survival factors may shift ratios of the Bcl-2 family towards cell death pathways (Fig. 6a). Short daylengths may also induce decreases in anti-apoptotic $\mathrm{BCl}-\mathrm{w}, \mathrm{BCl}-\mathrm{x}_{\mathrm{L}}$ and Bax expression, increases in expression of pro-apoptotic factors like Bax, Bak or Bcl- $\mathrm{x}_{\mathrm{S}^{\prime}}$ or changes in both. In addition, testicular expression has been determined for other members of this gene family: Blf-1 (A1), Bad, Bok, Bim (Bod), DIVA, Boo and Mcl-1. These proteins may also be involved in the apoptotic regulation of testicular regression, although the intricacies of their respective functions in the testis remain unknown (Print and Loveland, 2000).

In contrast, death by 'design' typically involves members of the tumour necrosis factor (TNF) family of death receptors and their ligands (Fig. 6b). In the testis, targeted cell death pathways involving the Fas system (Fas is a member of the TNF-receptor family) have been investigated in terms of their response to toxins, radiation exposure, mechanical injury and photoperiod-induced regression (Lee et al., 1997; Young et al., 1999; Richburg et al., 2000). Binding of Fas ligand (FasL, CD95L, APO-1L) to its death domaincontaining receptor, Fas (CD95, APO-1), has been established as a mechanism of cell death within both the healthy and pathological testis (Lee et al., 1997; Richburg et al., 2000). The Fas receptor contains a cytoplasmic 'death domain' motif, and can initiate the apoptotic cascade in targeted cells when bound by the Fas ligand (FasL) (Nagata and Goldstein, 1995; Lee et al., 1997). Fas receptor activation by FasL triggers downstream cleavage and activation of the caspase family of cysteine proteases that execute cell death (Fig. 6b). Expression of both Fas and FasL are upregulated in the testis of males exposed to Sertoli cell 


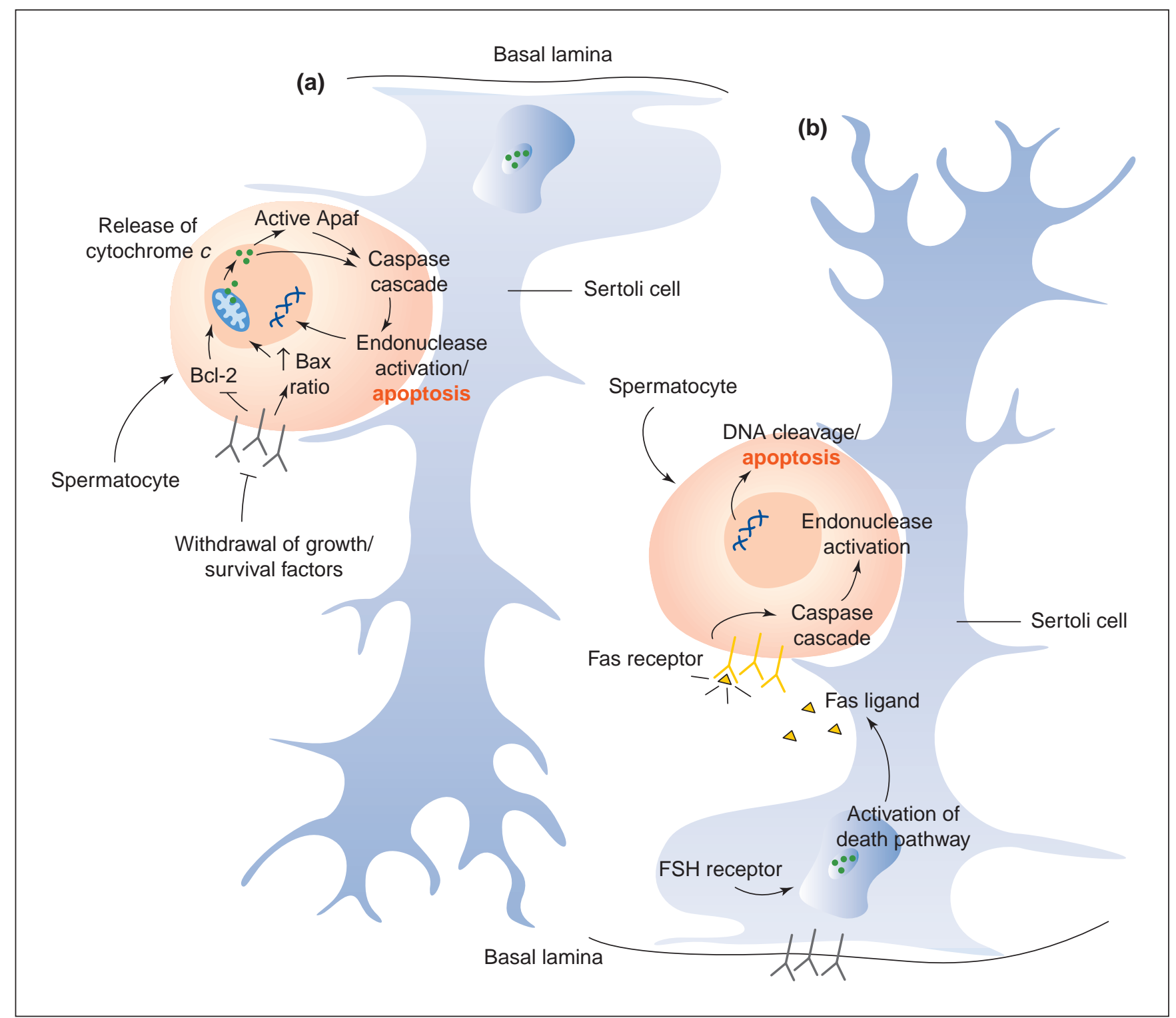

Fig. 6. Two hypothesized mechanisms of seasonal testicular regression. In both models, Sertoli cells regulate germ cell life and death within the testis. (a) Death by 'neglect': during testicular regression Sertoli cells could respond to endocrine changes, such as decreases in FSH concentration, by slowing or stopping secretion of factors crucial for spermatocyte growth and survival. Without survival signals, the ratio of B-cell lymphoma: leukaemia-2 (Bcl-2) family members within the germ cell can be altered, increasing Bcl-2-associated X protein (Bax) and other pro-apoptotic molecules, and preventing action of the anti-apoptotic Bcl-2 and related proteins. Increases in Bax and related pro-apoptotic stimuli can trigger mitochondria to release cytochrome $c$ and other proteins that can, alone or through binding of apoptotic protease activating factor 1 (Apaf) molecules, activate the caspase cascade. Once initiated, the proteolytic cascade of multiple caspase cleavages may culminate in endonuclease activation, DNA fragmentation and, ultimately, cell death. (b) In contrast, death by 'design' involves specific death receptors and their ligands, such as the tumour necrosis factor receptor superfamily, member 6 (Fas) system. In this model, changes in endocrine signals during regression activate Sertoli cell secretion of Fas ligand (FasL), or other tumour necrosis factor receptor (TNF-R) family ligands. FasL binds to its receptor, Fas, a cell-surface protein expressed by germ cells in the testes of many species. Once bound, the Fas system induces caspase activation, which results in endonuclease activity, DNA cleavage, and cell death.

toxins, various testicular injuries and withdrawal of hormonal support (Lee et al., 1997; Nandi et al., 1999).

During photoperiod-induced testicular regression, the Fas system is activated (Young et al., 1999). Short-day exposure evokes testicular Fas and FasL expression in adult white-footed mice; increases in Fas protein occur after 4 weeks of short-day exposure, well in advance of significant testicular regression (Young et al., 1999). Immunohistochemistry has localized Fas and FasL to adjacent germ cell and Sertoli cell plasma membranes, respectively (Lee et al., 
1997; Young et al., 1999). Declines in serum gonadotrophins may activate death pathway mechanisms in Sertoli cells, resulting in increased expression or secretion of FasL and, presumably, increased apoptosis in germ cells (Fig. 6b). The Fas apoptotic pathway may activate caspase cascades within the germ cells, leading to the DNA cleavage and cell death observed during seasonal testicular regression (Fig. 6b).

Other genes and gene families are involved in apoptosis, and may also play a significant role during seasonal testicular regression. The p53 protein is a critical component in the regulation of the cell cycle and is associated with the nuclear envelope in germ cells. The p53 protein can prevent replication of cells with DNA damage, and is involved in onset of apoptosis (Fisher, 1994). In unstressed germ cells, p53 protein is enriched in the nuclear envelope fraction, and has been hypothesized to play an important role in the regulation of germ cell differentiation by serving a 'proof-reading' function (Brash, 1996; Yin, et al., 1998). Heat stress to the testis results in increased germ cell apoptosis and induces p53 to move to the nucleus (Yin, et al., 1998). It is possible that the 'stress' of testosterone withdrawal and tubule collapse during late regression induces p53 to forgo its 'proof-reading' function, and move to the nucleus of germ cells, inducing their death. In addition, serum withdrawal and UVB irradiation induce mitochondrial release of cytochrome $c$ (Zhang et al., 2000) (Fig. 6a). In the cytoplasm, cytochrome $c$ serves as a cofactor for Apaf- 1 ; the heterodimer can then activate the effector caspase, caspase-3 (Li et al., 2000). Apoptosis in the regressing testis may be mediated by a variety of proteins involved with cell death as a result of changing endocrine conditions.

\section{Multiple apoptotic pathways}

It is unlikely that a single mechanism regulates apoptosis in the testis during seasonal regression, but rather that multiple apoptotic pathways are involved in the complex process of regression in seasonal breeders. Depending on the species, atrophy of the testis takes 3-14 weeks (Zucker et al., 1980). The internal environment of the testis changes substantially during this period of regression. Changes in tubule size, composition, endocrine support, and cell signalling occur continuously throughout the progression of testicular atrophy.

A mixture of death by neglect and design may be enlisted to complete testicular regression in seasonally breeding species. High testosterone concentrations and complete spermatogenesis characterize initial periods of regression in hamsters and white-footed mice. Early regression, characterized by initial withdrawal of gonadotrophins, may induce shifts in Bcl-2 family protein ratios (Fig. 6a). In addition, the Fas system, or a similar receptor in the TNF- $\alpha$ family may initiate testicular regression in this early period through Sertoli cell-specific signalling pathways (Fig. 6b). During early testicular regression in rodents, gonadotrophin withdrawal affects Sertoli cell function (Russell et al., 1987).
Presumably, gonadotrophin withdrawal induced by shortday exposure in white-footed mice induces Sertoli cells to upregulate FasL and hence increase the number of germ cells targeted for apoptosis.

As the testes continue to regress, the testicular environment changes substantially, and death pathways may include mitochondrial death effectors induced by the stress of survival factor withdrawal, or 'neglect'. Exposure to non-stimulatory environmental factors results in extensive decreases in concentrations of both gonadotrophin and testosterone. Withdrawal of testosterone results in a potentially stressful environment (Sinha Hikim and Swerdloff, 1999). The seminiferous tubules no longer support testosterone-driven spermatogenesis and collapse. Sertoli-germ cell-cell contact is lost as apoptotic cells are sloughed into the lumen, or phagocytosed. This environment may trigger additional, non-cell surface receptormediated pathways of apoptosis. The apoptotic events that mediate seasonal testicular regression probably result from activation of multiple cell death pathways.

Taken together, these findings indicate that normal levels of testicular apoptosis are increased as a result of seasonal hormonal changes, and that this escalation in programmed cell death serves to mediate seasonal testicular regression. Increases in apoptotic activity subside as testis mass reaches a nadir, and baseline apoptotic activity is characteristic of testicular recrudescence in seasonally breeding males. In addition, the Fas system is implicated as a potential mechanism for transmission of the apoptotic signal to germ cells during regression. However, multiple apoptotic pathways probably contribute to testicular regression. Finally, differences in both the contribution of testosterone and in the types of cell that undergo apoptosis differ between rodents and starlings, indicating that different cellular mechanisms, and possibly signals, have evolved at the level of the testis to address the problem of seasonal limitation of reproduction.

Preparation of this review and funding of the published experimental data from the authors' lab were supported by US Public Health Service Grant MH 57535, US National Science Foundation Grant IBN 97-23420, and NICHHD Training Grant T32-HD-07276 to K. A. Young.

\section{References}

Key references are identified by asterisks.

Allan DJ, Harmon BV and Kerr JFR (1987) Cell death in spermatogenesis. In Perspectives on Mammalian Cell Death pp 229-258 Ed. CS Potten. Oxford University Press, London

Bilinska B, Schmalz-Fraczek B, Sadowska J and Carreau S (2000) Localization of cytochrome P450 aromatase and estrogen receptors alpha and beta in testicular cells - an immunohistochemical study of the bank vole Acta Histochem 102 167-181

Billig H, Chun S-Y, Eisenhauer K and Hseuh AJW (1996) Gonadal cell apoptosis: hormone-regulated cell demise Human Reproduction Update 2 103-107

Brash DE (1996) Cellular proofreading Nature Medicine 2 25-26

Bronson FH (1989) Mammalian Reproductive Biology University of Chicago Press, Chicago

*Bronson FH and Heideman PD (1994) Seasonal regulation of reproduction 
in mammals. In The Physiology of Reproduction pp 541-584 Eds E Knobil and JD Neill. Raven Press, New York

Clermont Y and Morgentaler H (1955) Quantitative study of spermatogenesis in the hypophysectomized rat Endocrinology 57 369-382

Corrier DE, Mollenhaur HH, Clark DE, Hare MF and Elissalde MH (1985) Testicular degeneration and necrosis induced by dietary cobalt Veterinary Pathology 22 610-616

de Kretser DM and Kerr JB (1994) The cytology of the testis. In The Physiology of Reproduction pp 1177-1290 Eds E Knobil and J Neill. Raven Press, New York

Desjardins C and Lopez MJ (1983) Environmental cues evoke differential responses in pituitary-testicular function in deer mice Endocrinology 112 1398-1406

Ewing LL, Davis JC and Zirkin BR (1980) Regulation of testicular function: a spatial and temporal view International Reviews in Physiology 22 $41-115$

Fisher DE (1994) Apoptosis in cancer therapy: crossing the threshold Cell 78 $539-542$

Franca LR, Leal MC, Sasso-Cerri E, Vasconcelos A, Debeljuk L and Russell LD (2000) Cimetidine (Tagamet) is a reproductive toxicant in male rats affecting peritubular cells Biology Reproduction 63 1403-1412

Furuchi T, Masuko K, Nishimune Y, Obinata M and Matsui Y (1996) Inhibition of testicular germ cell apoptosis and differentiation in mice mis-expressing Bcl-2 in spermatogonia Development 122 1703-1709

Furuta I, Porkka-Heiskanen T, Scarbrough K, Tapanainen J, Turek FW and Hsueh AJ (1994) Photoperiod regulates testis cell apoptosis in Djungarian hamsters Biology of Reproduction 51 1315-1321

Hikim AP, Wang C, Leung A and Swerdloff RS (1995) Involvement of apoptosis in the induction of germ cell degeneration in adult rats after gonadotropin-releasing hormone antagonist treatment Endocrinology $1362770-2775$

Komatsu T, Tsubota T, Yamamoto Y, Atoji Y and Suzuki Y (1997) Seasonal changes in the immunolocalization of steroidogenic enzymes in the testes of the Japanese black bear (Ursus thibetanus japonicus) Journal of Veterinary Medical Science 59 521-529

Lee J, Richburg JH, Younkin SC and Boekelheide K (1997) The Fas system is a key regulator of germ cell apoptosis in the testis Endocrinology $\mathbf{1 3 8}$ 2081-2088

LeGrand EK (1997) An adaptationist view of apoptosis Quarterly Review of Biology 72 135-147

Li K, Li Y, Shelton JM, Richardson JA, Spencer E, Chen ZJ, Wang X and Williams RS (2000) Cytochrome c deficiency causes embryonic lethality and attenuates stress-induced apoptosis Cell 101 389-399

Matt KS and Stetson MH (1979) Hypothalamic-pituitary-gonadal interactions during spontaneous testicular recrudescence in golden hamsters Biology of Reproduction 20 739-746

Mikuz M (1985) Testicular torsion: simple grading for histological evaluation of tissue damage Applied Pathology 3 134-139

Nagata S and Goldstein P (1995) The Fas death factor Science 267 1449-1456

Nandi S, Banerjee PP and Zirkin BR (1999) Germ cell apoptosis in the testes of Sprague Dawley rats following testosterone withdrawal by ethane 1,2-dimethanesulfonate administration: relationship to Fas? Biology of Reproduction 61 70-75

Nelson RJ, Kita M, Blom JM and Rhyne-Grey J (1992) Photoperiod influences the critical caloric intake necessary to maintain reproduction among male deer mice (Peromyscus maniculatus) Biology of Reproduction 46 226-232

*Print CG and Loveland KL (2000) Germ cell suicide: new insights into apoptosis during spermatogenesis Bioessays 22 423-430

Print CG, Loveland KL, Gibson L, Meehan T, Stylianou A, Wreford N, de Kretser D, Metcalf D, Kontgen F, Adams JM and Cory S (1998) Apoptosis regulator bcl-w is essential for spermatogenesis but appears otherwise redundant Proceedings National Academy of Sciences USA $9512424-12431$

Reiter RJ (1972) Evidence for refractoriness of the pituitary-gonadal axis to the pineal gland in golden hamsters and its possible implications in annual reproductive rhythms Anatomical Record 173 365-371

*Richburg JH, Nanez A, Williams LR, Embree ME and Boekelheide K (2000) Sensitivity of testicular germ cells to toxicant-induced apoptosis in g/d mice that express a nonfunctional form of Fas ligand Endocrinology $\mathbf{1 4 1}$ 787-793

Russell LD, Alger LE and Nequin LG (1987) Hormonal control of pubertal spermatogenesis Endocrinology 120 1615-1632

Russell LD, Chandrashekar V, Bartke A and Hikim AP (1994) The hamster Sertoli cell in early testicular regression and early recrudescence: a stereological and endocrine study International Journal of Andrology 17 93-106

Schlatt S, deGeyter M, Kliesch S, Nieschlag E and Bergmann M (1995) Spontaneous recrudescence in the photoinhibited male Djungarian hamster, Photopus sungurous. Biology of Reproduction 53 1169-1177

Sharpe RM (1990) Intratesticular control of steroidogenesis Clinical Endocrinology (Oxford) 33 787-807

Shetty J, Marathe GK and Dighe RR (1996) Specific immunoneutralization of FSH leads to apoptotic cell death of the pachytene spermatocytes and spermatogonial cells in the rat Endocrinology 137 2179-2182

*Sinha Hikim AP and Swerdloff RS (1999) Hormonal and genetic control of germ cell apoptosis in the testis Reviews of Reproduction 4 38-47

Sinha Hikim AP, Rajavashisth TB, Sinha Hikim I, Lue Y, Bonavera JJ, Leung A, Wang C and Swerdloff RS (1997) Significance of apoptosis in the temporal and stage-specific loss of germ cells in the adult rat after gonadotropin deprivation Biology of Reproduction 57 1193-1201

Srivastava RK, Mi QS, Hardwick JM and Longo DL (1999) Deletion of the loop region of bcl-2 completely blocks paclitaxel-induced apoptosis Proceedings National Academy of Sciences USA 96 3775-3780

Tapanainen JS, Tilly JL, Vihko KK and Hsueh AJ (1993) Hormonal control of apoptotic cell death in the testis: gonadotropins and androgens as testicular cell survival factors Molecular Endocrinology 7 643-650

*Thompson EB (1994) Apoptosis and steroid hormones Molecular Endocrinology 8 665-673

Vaux DL and Strausser A (1996) The molecular biology of apoptosis Proceedings National Academy of Sciences USA 93 2239-2244

Wingfield JC and Kenagy GJ (1991) Natural regulation of reproductive cycles. In Vertebrate Endocrinology: Fundamental and Biomedical Implications Vol. 4B pp 303-342 Eds P Pang and M Schreibman. Academic Press, New York

Yin Y, Stahl BC, DeWolf WC and Morgentaler A (1998) p53-mediated germ cell quality control in spermatogenesis Developmental Biology 204 165-171

Young KA, Zirkin BR and Nelson RJ (1999) Short photoperiod induces testicular apoptosis in the white-footed mouse (Peromyscus leucopus) Endocrinology 140 1331-1339

Young KA, Zirkin BR and Nelson RJ (2000) Testicular regression in response to food restriction and short photoperiod in white-footed mice (Peromyscus leucopus) is mediated by apoptosis Biology of Reproduction 62 347-354

Young KA, Zirkin BR and Nelson RJ (2001a) Testicular apoptosis is downregulated during spontaneous recrudescence in white-footed mice (Peromyscus leucopus) Journal of Biological Rhythms 16 479-488

Young KA, Ball GF and Nelson RJ (2001b) Photoperiod-induced testicular apoptosis in European starlings (Sturnus vulgaris) Biology of Reproduction 64 706-713

Zhang XJ, Yan J, Cuttle L, Endre Z and Gobe G (2000) Escape from apoptosis after prolonged serum deprivation is associated with the regulation of the mitochondrial death pathway by bcl-x Biochemical and Biophysical Research Communications 277 487-493

Zhu Q, Meisinger J, Emanuele NV, Emanuele MA, LaPaglia N and Van Thiel DH (2000) Ethanol exposure enhances apoptosis within the testes Alcohol Clinical Experimental Research 24 1550-1556

Zucker I, Johnston PG and Frost D (1980) Comparative, physiological and biochronmetric analyses of rodent seasonal reproductive cycles. In Progress in Reproductive Biology Vol. 5 pp 102-133 Eds RJ Reiter and BK Follett. Karger, Basel 